\title{
R-DHAP Regimen
}

National Cancer Institute

\section{Source}

National Cancer Institute. R-DHAP Regimen. NCI Thesaurus. Code C140095.

A regimen consisting rituximab, dexamethasone, high dose cytarabine and cisplatin that can be used for the treatment of non-Hodgkin lymphoma (NHL). 